\title{
Genetic mutation spectrum of pantothenate kinase-associated neurodegeneration expanded by breakpoint sequencing in pantothenate kinase 2 gene
}

\author{
Dahae Yang ${ }^{1}$, Sanghyun $\mathrm{Cho}^{2}$, Sung Im Cho², Manjin Kim², Moon-Woo Seong ${ }^{2,3}$ and Sung Sup Park ${ }^{2,3^{*}}$ (D)
}

\begin{abstract}
Background: Neurodegeneration with brain iron accumulation describes a group of rare heterogeneous progressive neurodegenerative disorders characterized by excessive iron accumulation in the basal ganglia region. Pantothenate kinase-associated neurodegeneration (PKAN) is a major form of this disease.

Results: A total of 7 unrelated patients were diagnosed with PKAN in a single tertiary center from August 2009 to February 2018. Ten variants in PANK2 including three novel sequence variants and one large exonic deletion were detected. Sequencing of the breakpoint was performed to predict the mechanism of large deletion and AluSx3 and AluSz6 were found with approximately $97.3 \%$ sequence homology.

Conclusion: The findings support the disease-causing role of PANK2 and indicate the possibility that exonic deletion of PANK2 found in PKAN is mediated through Alu-mediated homologous recombination.
\end{abstract}

\section{Introduction}

Neurodegeneration with brain iron accumulation (NBIA) describes a group of rare heterogeneous progressive neurodegenerative disorders characterized by excessive iron accumulation in the basal ganglia region [1]. Pantothenate kinase-associated neurodegeneration (PKAN) accounts for $30-50 \%$ of NBIA cases with prominent extrapyramidal dysfunction, with estimated prevalence of one to two per million live births worldwide [2-4]. Diagnosis of PKAN usually consists of the clinical, radiological, and genetic background of the patient. Based on age, disease progression rate, and clinical symptoms, PKAN has two main presentations: a classic variant with severe

\footnotetext{
*Correspondence: sparkle@snu.ac.kr

2 Department of Laboratory Medicine, Seoul National University Hospital, 101 Daehak-ro, Jongno-gu, Seoul 03080, Korea
}

Full list of author information is available at the end of the article early-onset and an atypical variant with more variable phenotype with later age at onset $[5,6]$.

Pantothenate kinase 2 (PANK2), which is considered the causative gene of PKAN, is located on chromosome $20 \mathrm{p} 13$ and encodes a $50.5 \mathrm{kDa}$ mitochondrial enzyme called pantothenic acid kinase 2 (PanK-II), which is involved in the first regulatory step of coenzyme A biosynthesis [6]. Although the exact pathology of PKAN has not been established, debilitating variants in the PANK2 gene assumedly enable sufficient conversion of pantothenate to $4^{\prime}$-phosphopantothenate, leading to mitochondrial cysteine accumulation [7, 8]. Cysteine, which effectively binds iron, is thought to undergo rapid auto-oxidation, resulting in cytotoxic free radical production, which triggers cell damage [9]. Accordingly, most patients with PANK2 variant are known to exhibit a specific radiologic pattern of hyperintensity within the hypointense medial globus pallidus, called the eye-ofthe-tiger sign, on T2-weighted MR imaging [2]. original author(s) and the source, provide a link to the Creative Commons licence, and indicate if changes were made. The images or other third party material in this article are included in the article's Creative Commons licence, unless indicated otherwise in a credit line to the material. If material is not included in the article's Creative Commons licence and your intended use is not permitted by statutory regulation or exceeds the permitted use, you will need to obtain permission directly from the copyright holder. To view a copy of this licence, visit http://creativecommons.org/licenses/by/4.0/. The Creative Commons Public Domain Dedication waiver (http://creativeco mmons.org/publicdomain/zero/1.0/) applies to the data made available in this article, unless otherwise stated in a credit line to the data. 
In this study, the molecular spectrum was expanded and the possible underlying disease causing the mechanism of PKAN investigated.

\section{Materials and methods}

\section{Subjects}

From August 2009 to February 2018, patients with suspected PKAN referred to Seoul National University Hospital (SNUH) were enrolled in this study (Table 1, Fig. 1). The Institutional Review Board of SNUH approved the study.

\section{Sanger sequencing}

Genomic DNA was extracted from each patient's EDTA peripheral blood using Gentra Puregene DNA isolation kits (Gentra Systems, Inc., Minneapolis, MN, USA) according to the manufacturer's protocol. The extracted DNA was measured at $260 \mathrm{~nm}$ using a Nanodrop-2000 (Nanodrop Technologies, Wilmington, DE, USA) and DNA quality was confirmed based on $2 \%$ agarose gel electrophoresis. PCR was performed using in-house primers in the region containing the coding exons of the PANK2 gene and the flanking region of the intron. PCR products were electrophoresed on $2 \%$ agarose gel for verification by comparison with expected product size. The PCR product was purified using ExoSAP-IT (USB, Cleveland, OH, USA) at $37{ }^{\circ} \mathrm{C}$ for
$30 \mathrm{~min}$ and at $80^{\circ} \mathrm{C}$ for $15 \mathrm{~min}$. Twenty-five cycles of sequencing reaction $\left(95^{\circ} \mathrm{C}\right.$ for $10 \mathrm{~s}, 50^{\circ} \mathrm{C}$ for $5 \mathrm{~s}, 60^{\circ} \mathrm{C}$ for $4 \mathrm{~min}$ ) were performed with BigDye Terminator v3.1 Cycle Sequencing Kits (Applied Biosystems, Foster, CA, USA). Dye was purified with a SAM/X-Terminator solution and sequenced using an ABI 3730 Genetic Analyzer (Applied Biosystems, Inc., Foster City, CA, USA). The obtained results were compared with the reference sequence (GeneBank ID: NG_008131.3) using the Seqscape software v5.0 (Applied Biosystems).

3. Multiplex ligation-dependent probe amplification (MLPA)

Genomic rearrangement screening was performed using SALSA P120-B2 PANK2/PLA2G6 Kits (MRC Holland, Amsterdam, The Netherlands). First, $200 \mathrm{ng}$ of genomic DNA was mixed with RNase, denatured at $98{ }^{\circ} \mathrm{C}$, and hybridized with probe mix at $60^{\circ} \mathrm{C}$ for $16 \mathrm{~h}$. Ligation was performed at $54{ }^{\circ} \mathrm{C}$ for 15 min with the Ligase- 65 mix, followed by multiplex PCR using universal primers and SALSA polymerase for 35 cycles $\left(95{ }^{\circ} \mathrm{C}\right.$ denaturation for $30 \mathrm{~s}, 60{ }^{\circ} \mathrm{C}$ for $30 \mathrm{~s}, 72^{\circ} \mathrm{C}$ for $1 \mathrm{~min})$. Fragment analysis was performed on an ABI 3130 XL capillary sequencer (Applied Biosystems) with $1 \mu \mathrm{L}$ of final PCR product, $0.2 \mu \mathrm{L}$ of GeneScan-500ROX Size Standard (Applied Biosystems), and $8.8 \mu \mathrm{L}$ of $\mathrm{HiDi}$ Formamide (Applied Biosystems). Results were analyzed based on population normalization of peak height

Table 1 Clinical characteristics of patients enrolled in this study

\begin{tabular}{|c|c|c|c|c|c|c|}
\hline Patient & P1 & P3 & P4 & P5 & P6 & P7 \\
\hline Gender & $M$ & $\mathrm{~F}$ & $F$ & $M$ & $M$ & $M$ \\
\hline Age of onset (yr) & 30 & 8 & 14 months & 2 & 12 & 27 \\
\hline $\begin{array}{l}\text { Presenting symp- } \\
\text { toms }\end{array}$ & Right hand dystonia & $\begin{array}{l}\text { Decreased visual } \\
\text { acuity }\end{array}$ & Frequent fall & Development delay & Gait disturbance & Dystonia \\
\hline $\begin{array}{l}\text { Age at diagnosis } \\
(\mathrm{yr})\end{array}$ & 37 & 10 & 3 & 9 & 15 & 47 \\
\hline Dystonia & Limb, trunk & Limbs, trunk & Upper limbs & Neck, limbs & $\begin{array}{l}\text { Generalized dysto- } \\
\text { nia, opisthotonus }\end{array}$ & $\begin{array}{l}\text { General dystonia, } \\
\text { blepharospasm }\end{array}$ \\
\hline Bulbar symptoms & Dysarthria & Dysphagia & $\begin{array}{l}\text { Dysarthria, dys- } \\
\text { phagia }\end{array}$ & Dysarthria & & $\begin{array}{l}\text { Dysarthria, dys- } \\
\text { phagia }\end{array}$ \\
\hline $\begin{array}{l}\text { Gait/ posture } \\
\text { problems }\end{array}$ & $(-)$ & $\begin{array}{l}\text { Dystonic posturing, } \\
\text { unsteady }\end{array}$ & $\begin{array}{l}\text { Ataxic gait, tip } \\
\text { toeing }\end{array}$ & Dystonic gait & $\begin{array}{l}\text { Foot drop, tip } \\
\text { toeing }\end{array}$ & $\begin{array}{l}\text { Slow, reduced arm } \\
\text { swing, unsteady }\end{array}$ \\
\hline Others & $(-)$ & $\begin{array}{l}\text { Retinopathy, res- } \\
\text { piratory difficulty }\end{array}$ & $(-)$ & $\begin{array}{l}\text { autistic behavior, } \\
\text { seizure }\end{array}$ & cognitive decline & $\begin{array}{l}\text { insomnia, parkin- } \\
\text { sonism (bradykin- } \\
\text { esia, resting tremor, } \\
\text { postural instability) }\end{array}$ \\
\hline Family history & Denied & Denied & $A R$ & $A R$ & Denied & Sister: NE \\
\hline Eyes of tiger sign & $(+)$ & $(+)$ & $(+)$ & $(+)$ & $(+)$ & $(+)$ \\
\hline
\end{tabular}

$N E$ not examined

${ }^{*}$ Clinical data of $\mathrm{P} 2$ is unavailable 


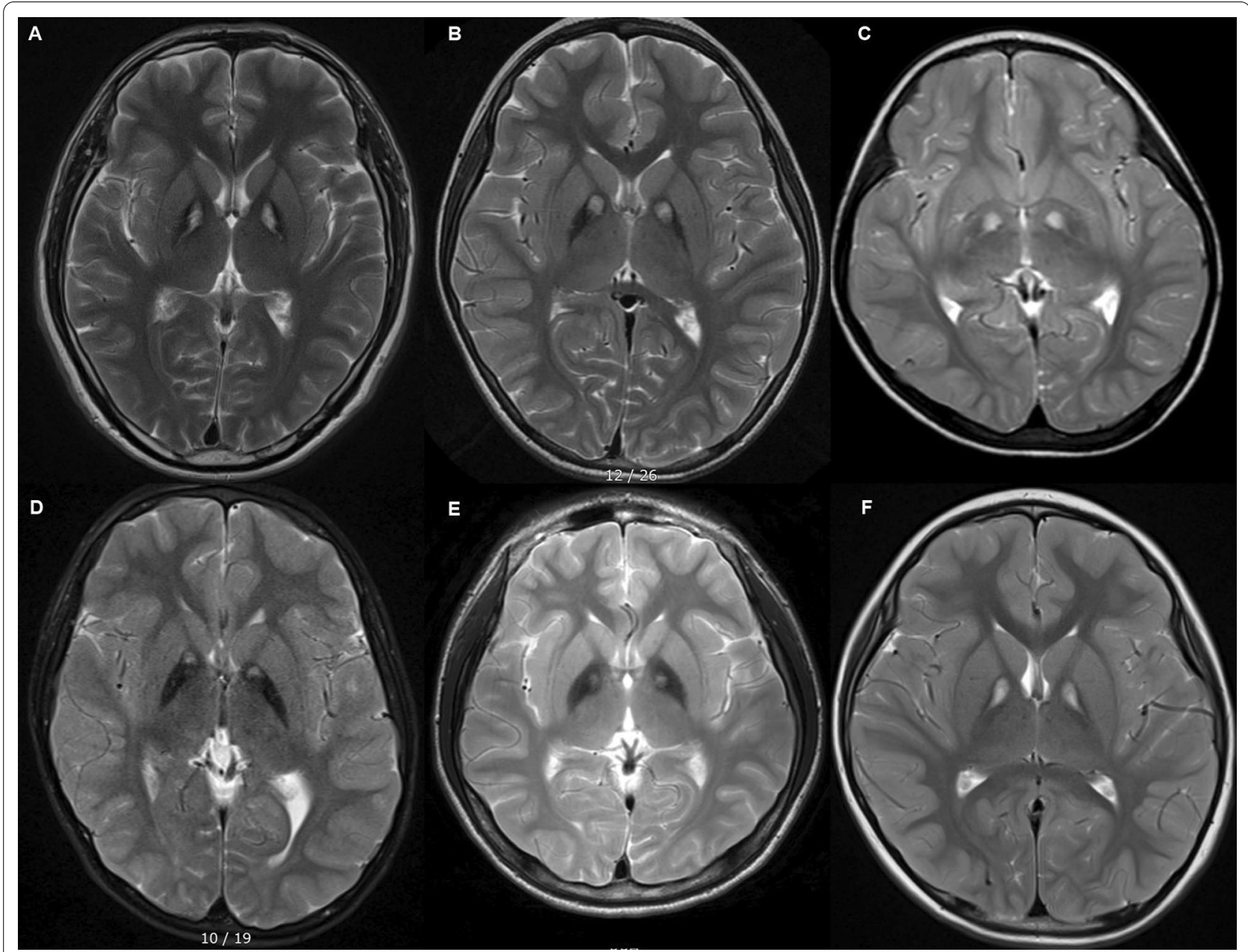

Fig. 1 MRI T2 image of A P1, B P3, C P4, D P5, E P6, F P7 showing symmetrical central hyperintensity surrounded by hypointensity in the globus pallidus giving "eye's of tiger sign" appearance

using Genemarker software v1.51 (SoftGenetics, State College, PA, USA).

\section{Deletion breakpoint evaluation}

A further experiment was conducted to identify the deletion breakpoint using the genomic DNA of an exon 3-4 deletion sample confirmed based on multiplex ligation-dependent probe amplification (MLPA). In-house primers were designed to examine the exon and intron regions of the 3-4 deletion areas, and long-PCR was performed using the Takara LA PCR System (Takara BIO INC, Shiga, Japan). Long-range PCR products were electrophoresed on $0.7 \%$ agarose gel at $90 \mathrm{~V}$ for $5 \mathrm{~h}$ to confirm PCR results.

Sanger sequencing was performed and the results compared with the reference sequence to determine the exact origin of fruiting and deletion size. To predict the mechanism of large deletion, RepeatMasker (http://www. repeatmasker.org/cgi-bin/WEBRepeatMasker/) was used to identify the type of repetitive elements and Clustal W (http: //www.genome.jp/tools-bin/clustalw/) software to perform multiple sequence alignments.

\section{Results}

1. Characteristics of variants spectrum in PANK2

A total of 10 variants were detected in 7 patients (Table 2). Missense variants (60\%) were most common, followed by small deletion (20\%), duplication $(10 \%)$, and exonic deletion (10\%). Six of the 10 identified variants were previously reported (five missense and one small deletion), and four (40\%) variants were novel. According to the American College of Medical Genetics and Genomics (ACMG) 2015 guidelines, 
Table 2 PANK2 gene variants detected using Sanger sequencing and MLPA

\begin{tabular}{|c|c|c|c|c|c|}
\hline Patient & Nucleotide change* & Amino acid change & Zygosity & ACMG & References \\
\hline \multirow[t]{2}{*}{ P1 } & C. $1133 A>G$ & p.Asp378Gly & Heterozygote & $L P$ & [22] \\
\hline & c.1273_1275delCTT & p.Leu425del & Heterozygote & $L P$ & [23] \\
\hline \multirow[t]{2}{*}{ P2 } & C. $1133 A>G$ & p.Asp378Gly & Heterozygote & $L P$ & [22] \\
\hline & C.1319G >C & p.Arg440Pro & Heterozygote & $L P$ & [11] \\
\hline \multirow[t]{2}{*}{ P3 } & $c .852 \mathrm{~T}>\mathrm{G}$ & p.Phe284Leu & Heterozygote & VUS & [24] \\
\hline & C.1319G >C & p.Arg440Pro & Heterozygote & $L P$ & [11] \\
\hline \multirow[t]{2}{*}{ P4 } & c.1210_1214dupAATTA & p.Tyr405* & Heterozygote & $L P$ & This study \\
\hline & C.1319G >C & p.Arg440Pro & Heterozygote & $L P$ & [11] \\
\hline \multirow[t]{2}{*}{ P5 } & c.1273_1275delCTT & p.Leu425del & Heterozygote & $L P$ & [23] \\
\hline & c. $1676 C>G$ & p.Ala559Gly & Heterozygote & VUS & [24] \\
\hline \multirow[t]{2}{*}{ P6 } & c. $1607 A>G$ & p.Tyr536Cys & Heterozygote & $L P$ & [24] \\
\hline & Exon 3-4 del & & Heterozygote & & This study \\
\hline \multirow[t]{2}{*}{ P7 } & c.823_824delCT & p.Leu275Valfs*16 & Heterozygote & $L P$ & This study \\
\hline & c. $1312 \mathrm{G}>\mathrm{T}$ & p.Ala438Ser & Heterozygote & VUS & This study \\
\hline
\end{tabular}

*Numbering is according to CDNA sequences (GenBank: NM_153638.2)

The $A$ of the ATG of the initiator methionine codon is denoted as nucleotide 1

MLPA, multiplex ligation-dependent probe amplification; ACMG, American College of Medical Genetics and Genomics; LP, likely pathogenic; VUS, variant of uncertain significance

c.1210_1214dupAATTA, c.823_824delCT were considered likely pathogenic (LP) and c.1315G > T was considered a variant of uncertain significance (VUS). Among the variants, c.1319G >C, p.Arg440Pro was the most frequent and identified in $42.6 \%(3 / 7)$ of patients.

\section{Discovery and verification of a large deletion}

Based on MLPA results, heterozygous exon 3-4 deletion was confirmed in patient 6 (P6; Table 2). To characterize the deletion breakpoint, a pair of in-house primers was constructed for sequencing. The product size of the alleles with deletion was approximately $270 \mathrm{bp}$ and the reference strand was approximately 5300 bp. Sequence analysis of the $270 \mathrm{bp}$ fragment confirmed the exon 3-4 deletion was a 5,016 bp deletion in the range of g.25,95430,969 with reference genome sequence NG_008131.3 (c.982-785_1413-2120del with the reference DNA sequence NM_153638.3). The sequence of the breakpoint was found to be AluSx3 and AluSz6 and sequence homology was approximately $97.3 \%$ (Fig. 2).

\section{Discussion}

PKAN is a progressive neurodegenerative disorder affecting movement, cognition, and behavior, and effective treatment does not exist [10]. Pantothenate kinase (PanK), a regulator in CoA biosynthesis, has three distinct types [7]. Among them, PanK-II is the sole mitochondria-targeted human PanK involved in various metabolic cycles with four human isoforms (PanK $1 \alpha$,
PanK1 $\beta$, PanK2, and PanK3) [11, 12]. The PanK2 encoded by the $P A N K 2$ gene is abundant in human neuronal tissues. The majority of the PANK2 variants known associated with PKAN result from little or no catalytic activity of PanK2 enzyme.

PKAN is a very rare disease, and only approximately 180 variants have been reported worldwide [13]. Most variants exist in the core catalytic region; in our study, all variants were within the range of 212-570 amino acids. Three hotspot variants (D378G, G521R, and $\mathrm{T} 528 \mathrm{M})$ in the PANK2 gene were previously reported [14], however, R440P was most common in the present study. Previously, Lim et al. [11] suggested the R440P variant, which occurred in $38 \%$ of PKAN patients, as a Korean-specific prevalent variant. In our case, R440P was reported with similar prevalence to the previous report, supporting the idea of a racial characteristic. Further research is needed to investigate the possibility of a founder effect on R440P.

In the present study, four novel variants, including three sequence variants and one large structural variant, in apparently unrelated families of PKAN were described.

The discovery of large deletions spanning exon 3-4 is noteworthy. Large deletions in PKAN have been reported in only a few studies and large deletions across exons are particularly rare $[2,11,12]$. In only one previous report, a large deletion was assumed to have occurred via two highly homologous sequences (92\%) encompassing the breakpoint, however, the authors did not perform further evaluation [12]. 

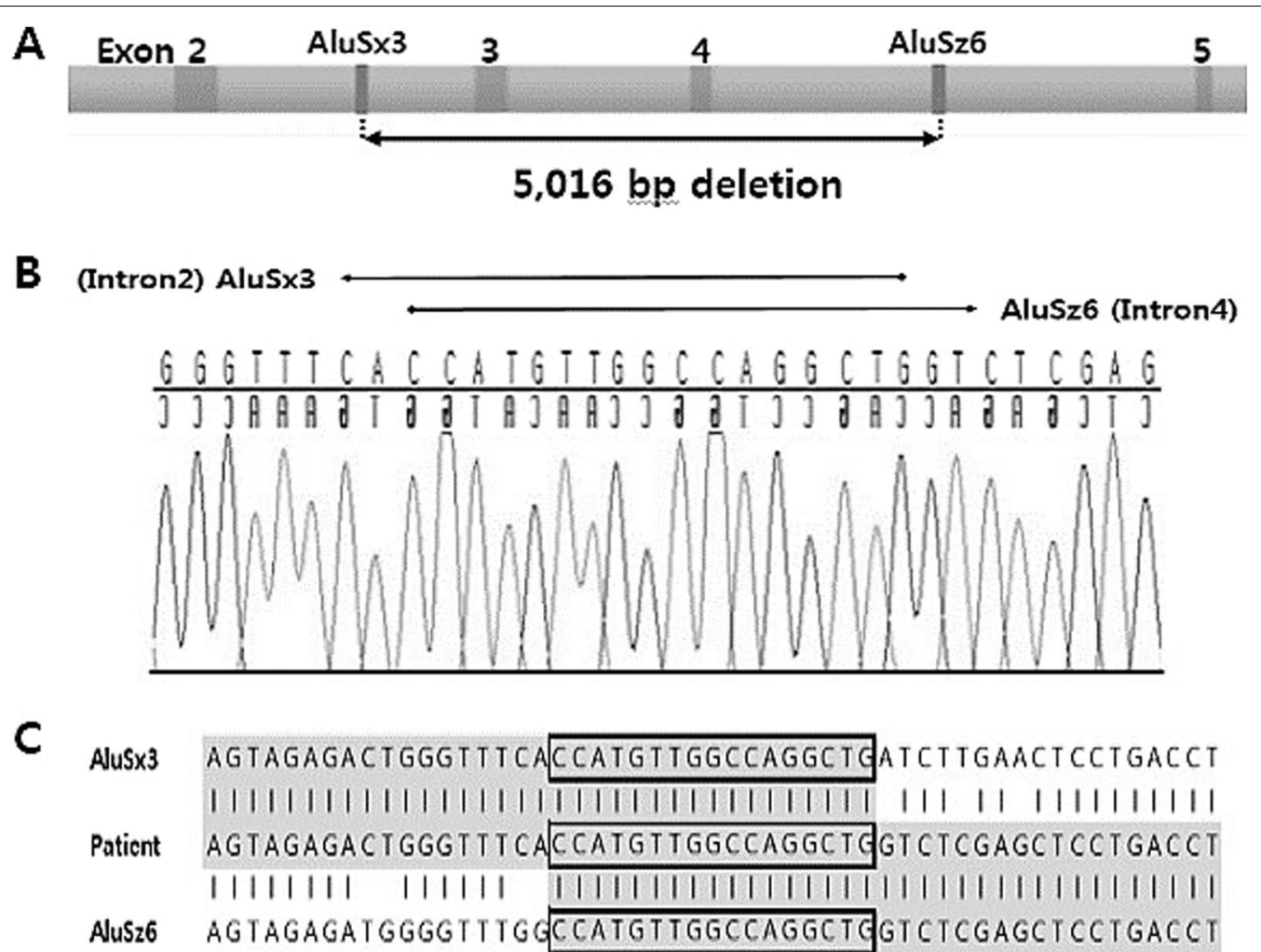

Fig. 2 Breakpoint mapping and characterization of the PANK2 exon 3-4 deletion. A Schematic representation of 5016 bp deletion breakpoints. B Sequence analysis showing breakpoints of the exon 3-4 large deletion. Breakpoints of this deletion are inside Alu repeats indicating Alu-mediated homologous recombination. C Sequence alignment at deletion breakpoints. Boxes indicate the Alu-sequence homology

To predict the mechanism of this deletion, the presence of repetitive elements in the vicinity of deletion breakpoints was examined for possible associations. The elements identified in the present study were AluSx3 and AluSz6. Alu elements are a family of short, interspersed elements that are RNA polymerase III transcribed retrotransposons which replicate via long interspersed element-encoded proteins and play an important role in genetic diversity $[15,16]$. More than one million Alu elements comprise roughly $10 \%$ of the human genome [17]. Although Alu repeats have no known biological function, Alu/Alu recombination has been reported to generate approximately $0.5 \%$ of human genetic diseases, particularly structural variations $[18,19]$. Recombination between these Alu elements tends to occur through highly homologous Alu sequences [20]. The concordance between the two $\mathrm{Alu}$ sequences found in the present study reached $97.3 \%$. Consequently, we infer the exon 3-4 deletion identified in this study was induced due to homologous recombination by AluSx3 and AluSz6.

Although in previous reports missense variants were suggested the main cause of early and late form PKAN [7], the occurrence of these diseases caused by truncated variants has consistently been reported [21]. Furthermore, null alleles were recently reported to be associated with more aggressive progression [13]. Therefore, finding the null variant of PKAN and understanding the mechanism of its occurrence is important for diagnosing and predicting the severity of the disease.

\section{Conclusion}

The present study results support the disease-causing effects of PANK2 in PKAN and are significant as the first report indicating that Alu-mediated homologous recombination is responsible for large deletion underlying PKAN. A large deletion in the PANK2 gene should not be overlooked in cases in which molecular diagnosis cannot be achieved through routine workup.

\section{Acknowledgements}

Not applicable.

\section{Authors' contributions}

DY, SHC, SIC and MK analyzed and interpreted the patient data. DY write the article. M-WS and SSP conceived, supervised and provided material. All authors attest that they meet the current criteria for Authorship. All authors read and approved the final manuscript. 


\section{Funding}

The authors have not received specific funding sources for this study.

\section{Availability of data and materials}

Data reasonably requested can be provided by the corresponding author after discussion with the Institutional Review Board.

\section{Declarations}

\section{Ethics approval and consent to participate}

This study was conducted with the approval of the Institutional Review Board of SNUH. (H-1804-137-940). Consent waiver was granted due to the retrospective nature of the study and no potential risk of harm to subjects.

\section{Consent for publication}

Not applicable.

\section{Competing interests}

The authors declare that they have no competing interests.

\section{Author details}

${ }^{1}$ Department of Laboratory Medicine, Kosin Gospel University Hospital, Busan, Korea. ${ }^{2}$ Department of Laboratory Medicine, Seoul National University Hospital, 101 Daehak-ro, Jongno-gu, Seoul 03080, Korea. ${ }^{3}$ Biomedical Research Institute, Seoul National University Hospital, Seoul, Korea.

Received: 11 August 2021 Accepted: 13 February 2022

Published online: 04 March 2022

\section{References}

1. Schneider SA. Neurodegeneration with brain iron accumulation. Curr Neurol Neurosci Rep. 2016;16:9.

2. Hayflick SJ, Westaway SK, Levinson B, Zhou B, Johnson MA, Ching KH et al. Genetic, clinical, and radiographic delineation of Hallervorden-Spatz syndrome. N Engl J Med. 2003;348:33-40.

3. Gordon N. Pantothenate kinase-associated neurodegeneration (Hallervorden-Spatz syndrome). Eur J Paediatr Neurol. 2002;6:243-7.

4. Brezavar D, Bonnen PE. Incidence of PKAN determined by bioinformatic and population-based analysis of $~ 140,000$ humans. Mol Genet Metab. 2019:128(4):463-9. https://doi.org/10.1016/j.ymgme.2019.09.002.

5. Leoni V, Strittmatter L, Zorzi G, Zibordi F, Dusi S, Garavaglia B, et al. Metabolic consequences of mitochondrial coenzyme A deficiency in patients with PANK2 mutations. Mol Genet Metab. 2012;105:463-71.

6. Angural A, Singh I, Mahajan A, Pandoh P, Dhar MK, Kaul S, Verma V, Rai E, Razdan S, Kishore Pandita K, Sharma S. A variation in PANK2 gene is causing Pantothenate kinase-associated Neurodegeneration in a family from Jammu and Kashmir_-India. Sci Rep. 2017;1:4834.

7. Zhou B, Westaway SK, Levinson B, Johnson MA, Gitschier J, Hayflick SJ. A novel pantothenate kinase gene (PANK2) is defective in HallervordenSpatz syndrome. Nat Genet. 2001;28:345-9.

8. Dansie LE, Reeves S, Miller K, Zano SP, Frank M, Pate C, et al. Physiological roles of the pantothenate kinases. Biochem Soc Trans. 2014;42:1033-6.

9. Hong BS, Senisterra G, Rabeh WM, Vedadi M, Leonardi R, Zhang YM, et al. Crystal structures of human pantothenate kinases. Insights into allosteric regulation and mutations linked to a neurodegeneration disorder. J Biol Chem. 2007;282:27984-93.

10. Sharma LK, Subramanian C, Yun MK, Frank MW, White SW, Rock CO, et al. A therapeutic approach to pantothenate kinase associated neurodegeneration. Nat Commun. 2018;9:4399.

11. Lim BC, Ki CS, Cho A, Hwang H, Kim KJ, Hwang YS, et al. Pantothenate kinase-associated neurodegeneration in Korea: recurrent R440P mutation in PANK2 and outcome of deep brain stimulation. Eur J Neurol. 2012;19:556-61.

12. Hartig MB, Hortnagel K, Garavaglia B, Zorzi G, Kmiec T, Klopstock T, et al. Genotypic and phenotypic spectrum of PANK2 mutations in patients with neurodegeneration with brain iron accumulation. Ann Neurol. 2006;59:248-56.
13. Chang $X$, Zhang J, Jiang Y, Wang J, Wu Y. Natural history and genotypephenotype correlation of pantothenate kinase-associated neurodegeneration. CNS Neurosci Ther. 2020;26:754-61.

14. Lee CH, Lu CS, Chuang WL, Yeh TH, Jung SM, Huang CL, et al. Phenotypes and genotypes of patients with pantothenate kinase-associated neurodegeneration in Asian and Caucasian populations: 2 cases and literature review. Sci World J. 2013;2013:860539.

15. Cordaux R, Batzer MA. The impact of retrotransposons on human genome evolution. Nat Rev Genet. 2009;10:691-703.

16. Batzer MA, Deininger PL. Alu repeats and human genomic diversity. Nat Rev Genet. 2002:3:370-9.

17. Lander ES, Linton LM, Birren B, Nusbaum C, Zody MC, Baldwin J, et al. Initial sequencing and analysis of the human genome. Nature. 2001;409:860-921.

18. Zhang G, Fukao T, Sakurai S, Yamada K, Michael Gibson K, Kondo N. Identification of Alu-mediated, large deletion-spanning exons 2-4 in a patient with mitochondrial acetoacetyl-CoA thiolase deficiency. Mol Genet Metab. 2006:89:222-6.

19. Elbarbary RA, Lucas BA, Maquat LE. Retrotransposons as regulators of gene expression. Science. 2016;351:aac7247.

20. Morales ME, White TB, Streva VA, DeFreece CB, Hedges DJ, Deininger PL. The contribution of alu elements to mutagenic DNA double-strand break repair. PLoS Genet. 2015;11:e1005016.

21. Dastsooz H, Nemati H, Fard MAF, Fardaei M, Faghihi MA. Novel mutations in PANK2 and PLA2G6 genes in patients with neurodegenerative disorders: two case reports. BMC Med Genet. 2017;18:87.

22. Seo JH, Song SK, Lee PH. A novel PANK2 mutation in a patient with atypical pantothenate-kinase-associated neurodegeneration presenting with adult-onset Parkinsonism. J Clin Neurol. 2009:5:192-4.

23. National Center for Biotechnology Information. ClinVar; [VCV000420144.2], https://www.ncbi.n/m.nih.gov/clinvar/variation/ VCV000420144.2. Accessed 23 June 2020.

24. Lee JH, Park J, Ryu HS, Park H, Kim YE, Hong JY, et al. Clinical heterogeneity of atypical pantothenate kinase-associated neurodegeneration in Koreans. J Mov Disord. 2016;9:20-7.

\section{Publisher's Note}

Springer Nature remains neutral with regard to jurisdictional claims in published maps and institutional affiliations.

Ready to submit your research? Choose BMC and benefit from:

- fast, convenient online submission

- thorough peer review by experienced researchers in your field

- rapid publication on acceptance

- support for research data, including large and complex data types

- gold Open Access which fosters wider collaboration and increased citations

- maximum visibility for your research: over 100M website views per year

At BMC, research is always in progress.

Learn more biomedcentral.com/submissions 